\title{
Polyisoprene Nanoparticles Prepared by Polymerization in Microemulsion
}

\author{
Y. Apolinar, L. F. Ramos, H. Saade, R. Díaz de León, and R. G. López \\ Departamento de Procesos de Polimerización, Centro de Investigación en Química Aplicada, \\ Boul. Ing. Enrique Reyna No. 140, Saltillo, 25253 Coah, Mexico \\ Correspondence should be addressed to R. G. López, glopez@ciqa.mx
}

Received 8 June 2010; Revised 21 July 2010; Accepted 6 August 2010

Academic Editor: Sang-Hee Cho

Copyright (c) 2010 Y. Apolinar et al. This is an open access article distributed under the Creative Commons Attribution License, which permits unrestricted use, distribution, and reproduction in any medium, provided the original work is properly cited.

Batch polymerization of isoprene was carried out at $25^{\circ} \mathrm{C}$ in a normal microemulsion stabilized with sodium dodecyl sulfate and initiated with the redox couple tert-butyl hydroperoxide/tetraethylene-pentamine. Characterization by transmission electronic microscopy showed that polyisoprene nanoparticles with number-average diameter close to $20 \mathrm{~nm}$ were obtained. The low molecular weights obtained, as determined by gel permeation chromatography, were probably due to chain scission as inferred from the oxidative ambient at which polymerization was carried out. Microstructure calculated from infrared spectroscopy data indicates that the obtained polyisoprene contains around $80 \%$ total 1,4 units, which is in accordance with its glass transition temperature $\left(-60.8^{\circ} \mathrm{C}\right)$ determined by differential scanning calorimetry.

\section{Introduction}

An improvement in the toughness of glassy polymers can be achieved by dispersion of rubber particles into the polymer matrix [1-3]. According to the literature, rubber particles with diameters between 1 and $2 \mu \mathrm{m}$ give the best results in the preparation of high-impact polystyrene (HIPS) [4, 5]. Nevertheless, it has been reported that smaller rubber particles combined with large ones (diameter $>1 \mu \mathrm{m}$ ) lead to a greater increase in the HIPS toughness [6]. Polyisoprene (PI) is a polymer used for preparing micrometric rubber particles, which in turn are used for successfully increasing the glassy polymers toughness [7, 8].

On this basis, it has been thought that it would be interesting to evaluate the effect of PI nanoparticles for improving the toughness of some glassy polymers. However, the reports on synthesis of PI nanoparticles are very scarce. Only two reports were found describing the synthesis of PI nanoparticles $[9,10]$. Cheong et al. polymerized isoprene in emulsions with low polymer content stabilized with different surfactants, using thermal and redox initiation systems and a very small concentration of tert-dodecyl mercaptan
$(t$-DM) in order to enhance the entry efficiency of radicals into micelles and particles [9]. They obtained PI particles with diameters in the range of $35 \mathrm{~nm}-100 \mathrm{~nm}$. Furthermore, when polymerizations were carried out at $25^{\circ} \mathrm{C}$ using redox systems, polymer gel content was zero in most cases. It is noticeable that polymerization times were very long $(\approx 40 \mathrm{~h})$ and that micrographs were not included in this report. On the other hand, Lorenz et al. [10] obtained PI particles between 80 and $200 \mathrm{~nm}$ when polymerizing isoprene at $72^{\circ} \mathrm{C}$ overnight in miniemulsions stabilized with various surfactants and only using thermal initiators. Surprisingly, as far as we know, microemulsion polymerization has not been used for synthesizing PI nanoparticles, in spite of the extensive use of this technique in research since 1980 for preparing polymeric nanoparticles with diameters $<50 \mathrm{~nm}$ $[11,12]$.

We report here a study on the synthesis of PI nanoparticles with average diameters close to $20 \mathrm{~nm}$ by polymerization at $25^{\circ} \mathrm{C}$ in a normal microemulsion stabilized with sodium dodecyl sulfate (SDS). The system tert-butyl hydroperoxide $(t$-BHP) and tetraethylene-pentamine (TEPA) was used as redox couple initiator. 


\section{Materials and Methods}

2.1. Materials. SDS (98.5\%), $t$-BHP (99.5\%), TEPA (>99\%) and $t$-DM $(99 \%)$, all from Aldrich were used as received. Isoprene (Aldrich) was distilled under reduced pressure and stored at $4^{\circ} \mathrm{C}$. Water was of tridistilled deionized grade.

2.2. Phase Diagram Determination. Microemulsion region at $25^{\circ} \mathrm{C}$ was determined by titration with isoprene of SDS/water mixtures at the following weight ratios: $2.5 / 97.5,5 / 95,10 / 90$, and $15 / 85$. Titration was stopped when the appearance of the mixture changed from transparent or translucent to opalescent, obtaining a first approximation to the boundary between the microemulsion region and the two phase region. Then, samples with isoprene content slightly higher and lower than the visually determined phase boundary were prepared by weighing each component and allowing each sample to reach equilibrium in a water bath at $25^{\circ} \mathrm{C}$ in order to determine the phase boundary more accurately. The normal microemulsion region corresponds to transparent or translucent samples that do not exhibit birefringence when observed through cross polarizers.

2.3. Polymerization. The polymerization was carried out at $25^{\circ} \mathrm{C}$ in a $200 \mathrm{~mL}$ jacketed glass reactor equipped with a reflux condenser and inlets for argon, monomer feed, mechanical agitation (450 rpm) and sampling. A $45^{\circ}$-pitched down flow four-bladed impeller was used. The procedure was as follows: $9.64 \mathrm{~g}$ of SDS, $86.78 \mathrm{~g}$ of water, $0.035 \mathrm{~g}$ of $t$ $\mathrm{BHP}$ and $0.0053 \mathrm{~g}$ of $t$-DM were charged into the reactor. This solution was heated to $25^{\circ} \mathrm{C}$ and bubbled with argon for $1 \mathrm{~h}$. Thereafter, $3.5 \mathrm{~g}$ of previously degasified isoprene were added and one minute later, $0.035 \mathrm{~g}$ of TEPA, were also added to the solution for starting the reaction, which was allowed to proceed for $24 \mathrm{~h}$. During the reaction, samples were withdrawn at given times to determine conversion (gravimetrically) and particle size. Samples from final latex were collected for characterization.

2.4. Characterization. Particle size of samples taken during polymerization was measured at $25^{\circ} \mathrm{C}$ in a Malvern Zetasizer Nano S90 quasielastic light scattering (QLS) apparatus equipped with an Argon laser $(\lambda=633 \mathrm{~nm})$. To measure the monomer-free average particle size, latex samples were diluted with water up to 200 times to remove nonreacted monomer. This diameter is the intensity-weighted average diameter $\left(D_{z}\right)$. Particle number density $\left(N_{p}\right)$ at time $t$ was calculated dividing the polymer concentration in the reaction mixture by the particle weight in accordance with the following:

$$
N_{P}=\frac{6 C_{o}(X / 100)}{\pi \rho_{p} D_{z}^{3}},
$$

where $C_{o}$ is the monomer initial concentration, $\rho_{p}$ the polymer density $(0.91 \mathrm{~g} / \mathrm{mL})[13]$ and $X$ and $D_{z}$ the conversion and the average diameter at time $t$, respectively.

Particle size of a sample from final latex was measured in a JEOL 1200 eXII transmission electronic microscope.

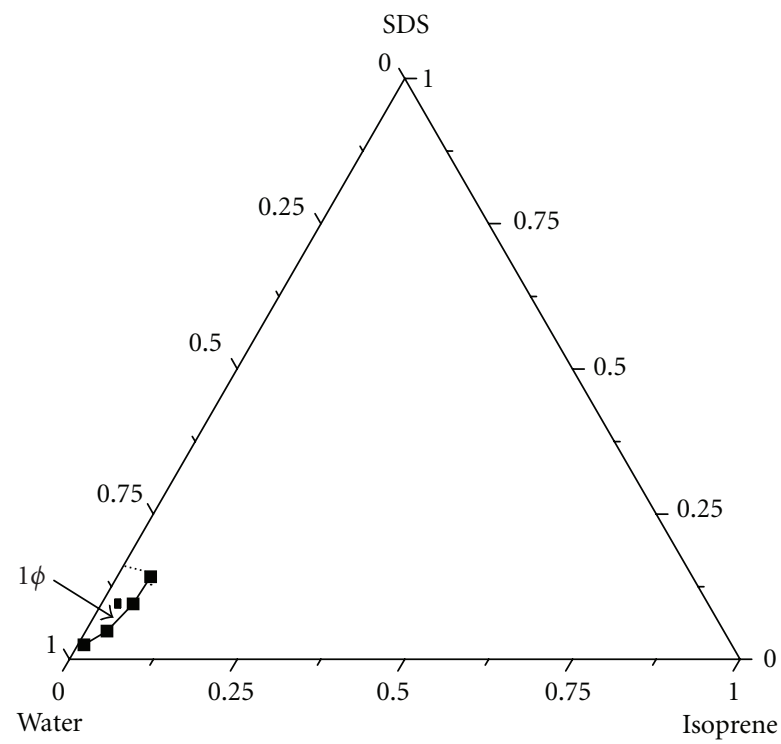

Figure 1: Partial phase diagram at $25^{\circ} \mathrm{C}$ of SDS/water/isoprene showing the normal microemulsion region $(1 \phi)$. Composition of the microemulsion where polymerization was carried out is shown by (ם).

Previous to this measurement, polymer in the latex sample was crosslinked using a UV lamp $(10 \mathrm{~W}, \lambda=280-315 \mathrm{~nm})$ for $6 \mathrm{~h}$. Then a drop of latex diluted up to 20 times was deposited on a copper grid, which was subsequently stained with osmium tetroxide. Polymer molecular weight distribution in the final latex was measured in a Hewlett-Packard110 Gel Permeation Chromatograph (GPC) equipped with a refractive index detector. HPLC-grade tetrahydrofurane (THF) was used as mobile phase. The GPC was calibrated using 12 narrow polystyrene standards (Polyscience) with molecular weights ranging $162-6.3 \times 10^{6} \mathrm{~g} / \mathrm{mol}$. Molecular weights $(M)$ were calculated with the viscosimetric equation for PI in THF, $[\eta]=1.77 \times 10^{-4} M^{0.735}[14]$. Glass transition temperature $\left(T_{g}\right)$ determination was carried out in a modulated differential scanning calorimeter (DSC) TA Instruments 2920. Measurement was performed at a heating rate of $10^{\circ} \mathrm{C} / \mathrm{min}$ in the range $-120^{\circ} \mathrm{C}$ to $-10^{\circ} \mathrm{C}$, under a nitrogen flow of $50 \mathrm{~mL} / \mathrm{min}$. After the first heating scan, samples were quenched and a second scan was carried out at equal heating rate $\left(10^{\circ} \mathrm{C} / \mathrm{min}\right)$. The glass transition temperature was evaluated from the second scan by analyzing the reversible heat flow signal using the criteria of half-height. Infrared spectroscopy was carried out in an FT-Infrared Spectrophotometer Termo Nicolet/Mangro-550. For this, the dried polymer sample was grinded with potassium bromide powder and subsequently pressed to form a disk, which was analyzed in the apparatus.

\section{Results and Discussion}

Partial phase diagram for the system isoprene/water/SDS at $25^{\circ} \mathrm{C}$ is shown in Figure 1. Samples within the one-phase region $(1 \phi)$ are transparent and very fluid, which suggests 


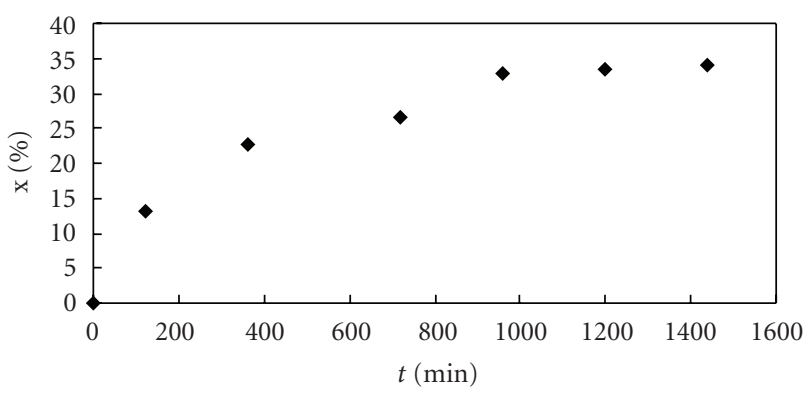

FIGURE 2: Evolution of monomer conversion in the polymerization of isoprene in a normal microemulsion at $25^{\circ} \mathrm{C}$.

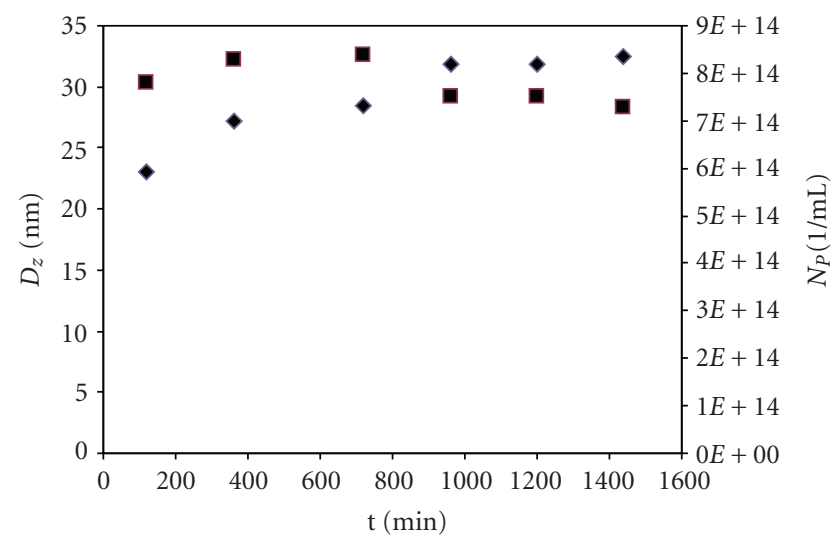

FIGURE 3: Evolution of the average particle diameter measured by QLS, $D_{z},(\checkmark)$ and the particle number density, $N_{p},(\boldsymbol{\square})$ in the polymerization of isoprene in a normal microemulsion at $25^{\circ} \mathrm{C}$.

that this region is a normal microemulsion one. To carry out the polymerization, a composition inside the microemulsion region was chosen. The square in Figure 1 indicates this composition.

Evolution of monomer conversion $(\mathrm{X})$ versus polymerization time is shown in Figure 2. As can be seen in this figure, polymerization proceeds very slowly and the final conversion is relatively low. Cheong et al. [9] indicate that low yields in emulsion polymerization of isoprene were possible due to its low propagation rate constant $\left(k_{p}\right)$. These authors argue that low $k_{p}$ of isoprene would lead to a low propagation rate inside the latex particles as well as to a long aqueous-phase lifetime before particle entry, and hence low entry efficiency, due to termination of isoprene oligomers in the aqueous phase. For increasing the final conversion in emulsion polymerization of isoprene, Cheong et al. added $t$-DM to the reaction mixture [9]. It is believed that mercaptan enhances entry efficiency in particles through chain transfer from a sulfate (when a persulfate is used as initiator) or oligomeric isoprene radical to the thiol, which may enter micelles/particles directly and/or form an entering species after fewer propagation steps in comparison with those required for oligomeric isoprene radicals [15]. In our case, in spite of using $t$-DM, final conversion after $24 \mathrm{~h}$ reaction was about $35 \%$. This result could be due to the low concentrations of initiator $(6.6 \mathrm{mM})$ and transfer agent (0.3 mM) used.

The average particle diameter measured by QLS $\left(D_{z}\right)$ and the particle number density $\left(N_{p}\right)$ versus polymerization time are depicted in Figure 3. Particle size increases sharply at the beginning of the polymerization; after that it increases slowly and stabilizes at $34-34 \mathrm{~nm}$ during the last third of the polymerization. It is noteworthy that monomer conversion also stabilizes about $35 \%$ in the same period of the polymerization. This evolution of particle size could be explained as follows. While, most of the isoprene polymerization conducted in our study proceeds slowly, there is a fast polymerization period occurring at the beginning of the reaction. In this period $(0-400 \mathrm{~min})$, the relatively high monomer availability in the micelles favors the simultaneous nucleation and growing of the particles, which is reflected in the relatively fast increase in the monomer conversion (Figure 2) and in the sharp increase in $D_{z}$ and $N_{p}$ (Figure 3). Then, between 400 and $1000 \mathrm{~min}$, the polymerization becomes slower, probably because the drop in the monomer concentration in the system starts to become important. At the end of this period, between 800 and $1000 \mathrm{~min}$, the $N_{p}$ curve in Figure 3 shows a decrease whereas the growth rate of the particle size appears to increase. After that, in the last part of the polymerization, the particle size shows a very small increase, while $N_{p}$ decreases slightly. It is believed that the observed decrease in $N_{p}$ from approximately $27 \%$ in conversion is due to interparticle coalescence. This phenomenon can be explained taking into account the very low glass transition temperature $\left(T_{g}\right)$ of polyisoprene, typically much lower than room temperature [16]. Because of this, particles are very soft at the temperature at which polymerization was carried out, which would lead to an increase in the fraction of the interparticle collisions resulting in coalescence.

Figure 4 shows a micrograph of a sample taken at the end of polymerization along the histogram of particle size made from measuring more than 250 particles. From this figure it is evident that spherical nanoparticles of polyisoprene can be obtained by microemulsion polymerization. Particle size data in the histogram allowed us to calculate a value of $27.0 \mathrm{~nm}$ for weight-average diameter $(D w)$ and of $22.2 \mathrm{~nm}$ for number-average diameter (Dn). Polydispersity calculated as $D w / D n$ show a value of 1.2 , which indicates a relatively broad particle size distribution. Average particle size obtained here is in accordance with typical values obtained in microemulsion polymerization. However, such broad particle size distribution as that obtained in our study is not common in this type of polymerization, in spite of the particle nucleation through the whole polymerization, as a consequence of the high content of surfactant in the parent microemulsions $[11,12]$. It is believed that this broad particle size distribution could be explained on the basis of the interparticle coalescence. It is a well-known fact that in a particle population the coalescence between larger particles contributes to the widening of the particle size distribution.

The result of GPC analysis for a sample taken at the end of polymerization is shown in Figure 5. Weight-average 


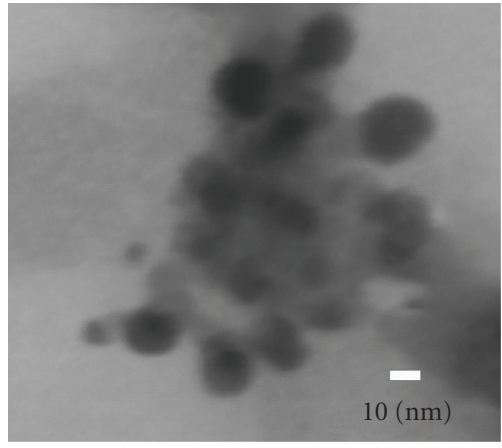

(a)

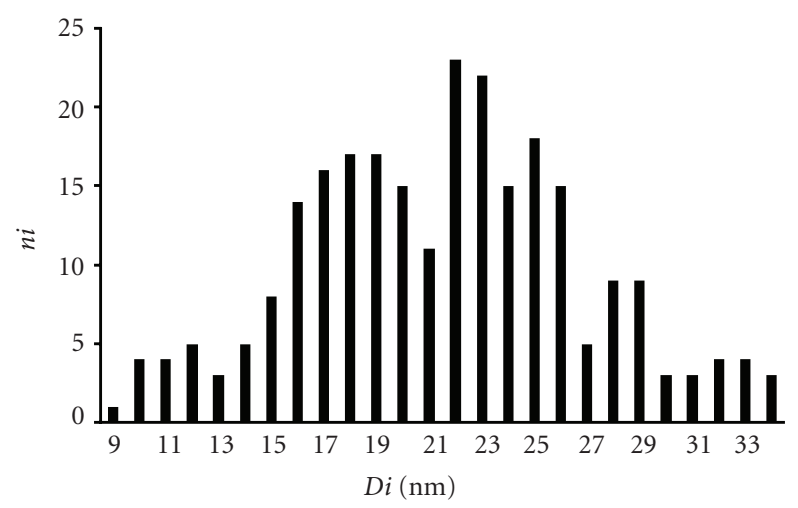

(b)

FIgURE 4: TEM micrography (a) and the particle diameter histogram (b) of final latex sample prepared by polymerization of isoprene in a normal microemulsion at $25^{\circ} \mathrm{C}$.

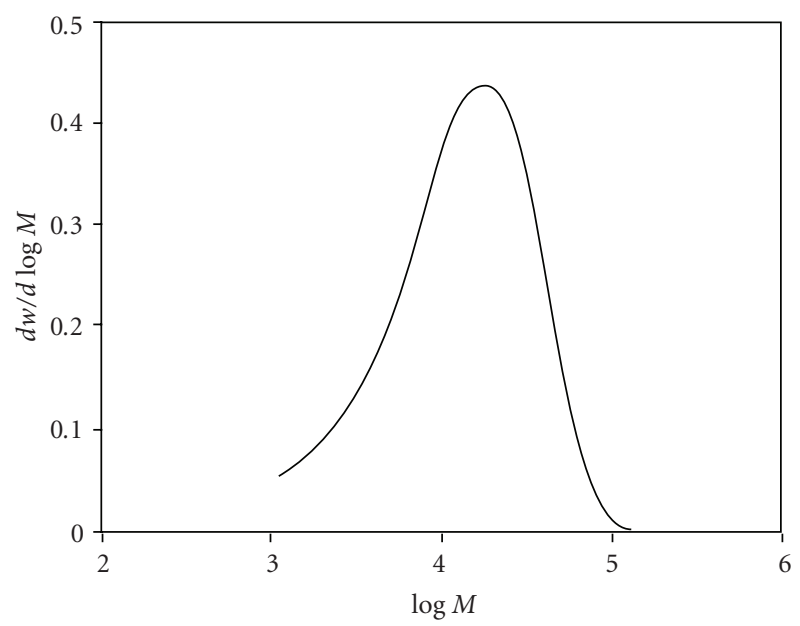

FIgURE 5: Molecular weight distribution of polyisoprene obtained at the end of the polymerization in a normal microemulsion at $25^{\circ} \mathrm{C}$.

molecular weight $(\mathrm{Mw})$ and number-average molecular weight $(\mathrm{Mn})$ were determined from molecular weight distribution (MWD) data as $20.4 \times 10^{3}$ and $10.1 \times 10^{3} \mathrm{~g} / \mathrm{mol}$, respectively. Figure 5 shows a monomodal MWD, which suggests that the final size of polymer chains is determined by only one main dominant mechanism. Based on the low

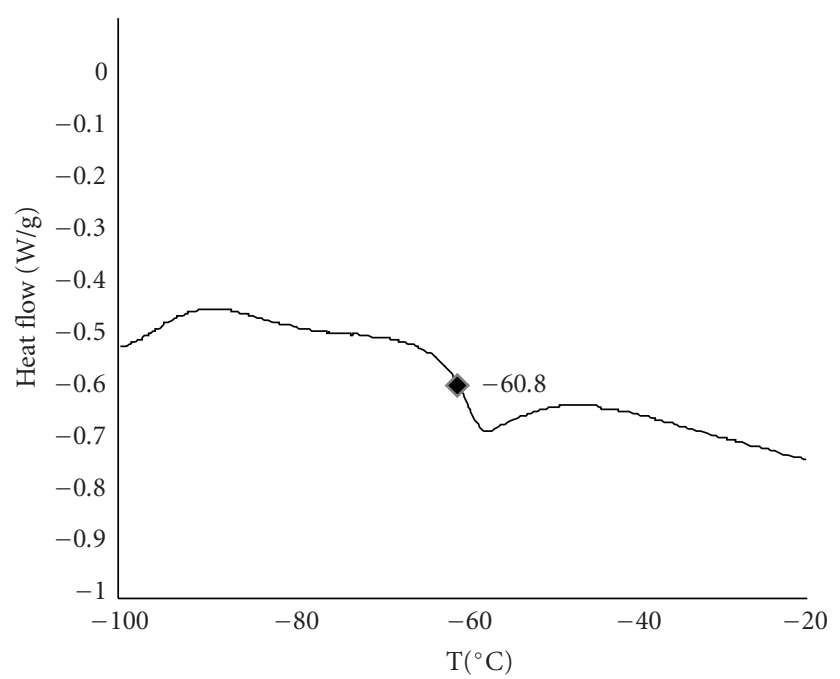

FIGURE 6: Thermogram obtained by DSC of a final sample of polyisoprene prepared by polymerization in a normal microemulsion at $25^{\circ} \mathrm{C}$.

molecular weight values obtained in this polymerization, it is believed that the dominant mechanism would be one that would promote the formation of short chains, such as chain scission, which occurs during the polymerization by oxidative degradation, as has been seen in polydienes exposed to oxygen $[17,18]$ or in polyisoprene in the presence of hydroperoxides [9], as in our case. The absence of a shoulder in the high molecular weight region would indicate a negligible contribution of crosslinking reactions. This could be ascribed to the relatively low temperature at which polymerization was carried out and the relatively low final conversion, considering that crosslinking reaction becomes important in the last stages of the polymerizations where high final conversions (>90\%) are attained [9]. Another possible mechanism of polymer chain termination is that resulting from the interparticle coalescence. When this phenomenon occurs between two particles containing polymer growing chains, the probability of bimolecular termination increases as the polymer particle size decreases. The average diameter of polymer particles obtained in our study suggests that bimolecular termination cannot be discarded as a contributing mechanism to the final population of polymer chains. Nevertheless, according to Figure 3, the interparticle coalescence becomes important from 8001000 min in reaction time (or $27 \%-32 \%$ in conversion) that is, near the end of the reaction (see Figure 2). This indicates that the contribution of the polymer chains resulting from bimolecular termination to the final population of polymer chains would be very small.

Polyisoprene obtained at the end of the polymerization shows a $T_{g}$ of $-60.8^{\circ} \mathrm{C}$ (see Figure 6). The effect of both microstructure and molecular weight on $T_{g}$ of polyisoprene has been reported in a number of studies [17-23]. According to Cowie [19] and Kow et al. [21], $T_{g}$ becomes molecular weight independent above $\mathrm{Mn} \approx 9-10 \times 10^{3} \mathrm{~g} / \mathrm{mol}$. As the polyisoprene obtained in 


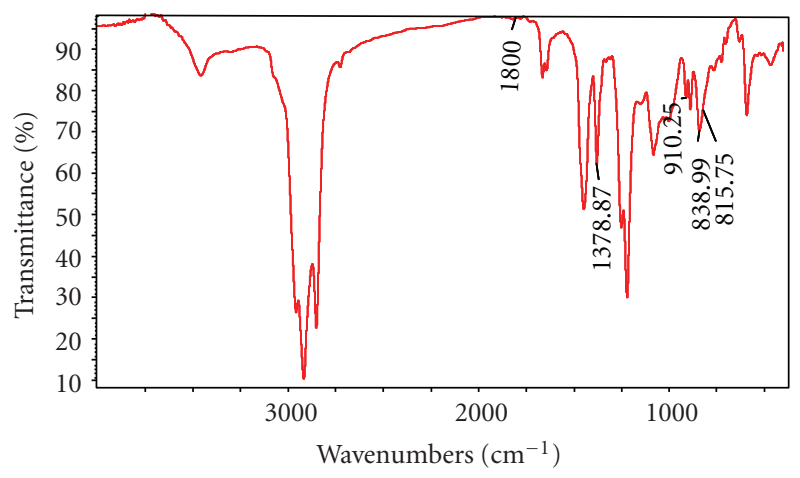

FIGURE 7: FT-IR spectra of polyisoprene obtained at the end of the polymerization in a normal microemulsion at $25^{\circ} \mathrm{C}$.

our study has a $\mathrm{Mn}=10.1 \times 10^{3} \mathrm{~g} / \mathrm{mol}$ it is believed that $T_{g}$ was mainly determined by its microstructure. About the $T_{g}$-microstructure relationship, Widmaier and Meyer [20] determined $T_{g}$ values for a series of polyisoprene samples obtained by anionic polymerization with different microstructures. They found $T_{g}$ values in the range -71 to $-36^{\circ} \mathrm{C}$ for 3,4 units content ranging from 9 to $49 \%$, with a direct dependence $T_{g}-3,4$ content. The increase of $T_{g}$ with 3,4 units content was explained by Widmaier and Meyer adducing that the steric hindrance resulting from the sidechain vinyl groups lead to stiffening of polymer chains. May be due to its obviousness because of the absence of 1,2 units in the samples of polyisoprene, they did not mention the inverse dependence between $T_{g}$ and total 1,4 units content. Kow et al. [21] also reported an inverse dependence between $T_{g}$ and total 1,4 content. So, according to the findings reported by Widmaier and Meyer, a polyisoprene with a $T_{g}$ value of $-60.8^{\circ} \mathrm{C}$, as in our case, should be expected to have around $80 \%$ of total 1,4 units.

According to the literature $[24,25]$ it is possible to know the microstructure of polyisoprene from FT-IR spectroscopy. Tsurugi et al. [24] developed a method for calculating the cis1,4 content in a polyisoprene based on its FT-IR spectra. This method uses the following:

$$
\begin{aligned}
D_{839} & =\log \left(\frac{I_{815}}{I_{839}}\right), \\
D_{1379} & =\log \left(\frac{I_{1379}}{I_{1800}}\right),
\end{aligned}
$$

where $I$ indicates the transmittances at the corresponding wave lengths. The ratio $D_{839} / D_{1379}$ is directly proportional to the cis-1,4 content in a correlation chart included in the report of Tsurugi et al. [24]. Figure 7 shows the FT-IR spectra of the polyisoprene obtained at the end of the polymerization. Substitution of the corresponding transmittance values in (2) and using the chart in reference [23] allowed us to obtain a value of $30 \%$ cis- 1,4 content in the polyisoprene prepared in this work. In order to determine the complete microstructure we calculated the areas under the peaks at $839 \mathrm{~cm}^{-1}$ for cis-1,4 units, $890 \mathrm{~cm}^{-1}$ for 3,4 units and $910 \mathrm{~cm}^{-1}$ for 1,2 units, using the software of our spectrometer. After that, the calculated areas were affected by a factor for rendering the contribution of the area under the peak corresponding to $c i s-1,4$ units in $30 \%$. In this way, the 3,4 units content was $8.2 \%$ and that of 1,2 , was $8.4 \%$. The difference with $100 \%$, that is, $53.4 \%$, corresponds to the trans $-1,4$ content. The dominance of the trans-1,4 units agrees with that of polyisoprene synthesized in emulsion polymerization by other groups $[9,25]$. Furthermore, the total content of 1,4 units $(\approx 83 \%)$ calculated by Tsurugi's method is in accordance with our previous estimation of about $80 \%$ based in the $T_{g}$ value of the polyisoprene synthesized in this study.

\section{Conclusions}

Batch polymerization of isoprene carried out in a normal microemulsion proceeded very slowly and the final conversion was relatively low. This behavior was ascribed to the low concentrations of initiator and/or the transfer agent originally added to enhance the micelle/particle radicals entry. Nanoparticles obtained showed a number-average diameter close to $20 \mathrm{~nm}$ and a relatively broad particle size distribution. It is believed that the latter is promoted by particle coalescence. Low molecular weight and monomodal molecular weight distribution of obtained polyisoprene suggest that the final size of polymer chains was determined by only one main dominant mechanism, which promotes the formation of short chains, such as chain scission. Microstructure determined by Tsurugi's method shows that the polyisoprene synthesized in this study contains around $80 \% 1,4$ units, which matches with its $T_{g}$ value $\left(-60.8^{\circ} \mathrm{C}\right)$.

\section{Acknowledgments}

The authors grateful to Pablo Acuña and Julieta Sánchez for their technical assistance.

\section{References}

[1] L. Rios-Guerrero, H. Keskkula, and D. R. Paul, "Deformation processes in high impact polystyrene as revealed by analysis of arrested cracks," Polymer, vol. 41, no. 14, pp. 5415-5421, 2000.

[2] J. Rovere, C. A. Correa, V. G. Grassi, and M. F. Dal Pizzol, "Role of the rubber particle and polybutadiene cis content on the toughness of high impact polystyrene," Journal of Materials Science, vol. 43, no. 3, pp. 952-959, 2008.

[3] F. M. B. Coutinho, M. P. M. Costa, M. J. O. C. Guimarães, and B. G. Soares, "Preparation and characterization of highimpact polystyrene using different types of polybutadiene," Journal of Applied Polymer Science, vol. 108, no. 1, pp. 406-413, 2008.

[4] A. M. Donald and E. J. Kramer, "Internal structure of rubber particles and craze break-down in high-impact polystyrene (HIPS)," Journal of Materials Science, vol. 17, no. 8, pp. 23512358, 1982.

[5] A. M. Donald and E. J. Kramer, "Craze initiation and growth in high-impact polystyrene," Journal of Applied Polymer Science, vol. 27, no. 10, pp. 3729-3741, 1982.

[6] Y. Okamoto, H. Miyagi, M. Kakugo, and K. Takahashi, "Impact improvement mechanism of HIPS with bimodal 
distribution of rubber particle size," Macromolecules, vol. 24, no. 20 , pp. 5639-5644, 1991.

[7] S. Sangribsub and P. Tangboriboonrat, "Toughness enhancement of high-impact polystyrene based on $\gamma$-radiation vulcanized natural rubber latex by using block copolymer," Journal of Applied Polymer Science, vol. 85, no. 6, pp. 1307-1316, 2002.

[8] S. B. Neoh and A. S. Hashim, "Highly grafted polystyrenemodified natural rubber as toughener for polystyrene," Journal of Applied Polymer Science, vol. 93, no. 4, pp. 1660-1665, 2004.

[9] I. W. Cheong, C. M. Fellows, and R. G. Gilbert, "Synthesis and cross-linking of polyisoprene latexes," Polymer, vol. 45, no. 3, pp. 769-781, 2004.

[10] M. R. Lorenz, M. V. Kohnle, M. Dass et al., "Synthesis of fluorescent polyisoprene nanoparticles and their uptake into various cells," Macromolecular Bioscience, vol. 8, no. 8, pp. 711727, 2008.

[11] J. E. Puig, "Microemulsion polymerization," in The Polymeric Materials Encyclopedia. Synthesis, Properties and Applications, J. C. Salamone, Ed., vol. 6, CRC Press, Boca Raton, Fla, USA, 1996.

[12] C. C. Co, R. de Vries, and E. W. Kaler, in Reactions and Synthesis in Surfactant Systems, J. Texter, Ed., vol. 100 of Surfactant Sci. Series, chapter 22, Marcel Dekker, New York, NY, USA, 2001.

[13] J. Brandrup and E. H. Immergut, Polymer Handbook, chapter V, John Wiley \& Sons, Hoboken, NJ, USA, 3rd edition, 1989.

[14] http://www.ampolymer.com/.

[15] E. M. Verdurmen, J. M. Verstegen, and A. L. German, "Particle growth in butadiene emulsion polymerization. 4 . The promoting effect of mercaptans," Macromolecular Chemistry and Physics, vol. 195, no. 2, pp. 647-659, 1994.

[16] G. Odian, Principles of Polymerization, chapter 8, Wiley, New York, NY, USA, 2004.

[17] L. Gonon and J. L. Gardette, "Photooxidation mechanism of styrene-isoprene copolymer: evolution of the profile of oxidation according to the composition," Polymer, vol. 41, no. 5, pp. 1669-1678, 2000.

[18] J. A. Blach, G. S. Watson, W. K. Busfield, and S. Myhra, "Photo-oxidative degradation in polyisoprene: surface characterization and analysis by atomic force microscopy," Polymer International, vol. 51, no. 1, pp. 12-20, 2002.

[19] J. M. G. Cowie, "Glass transition temperature-molecular weight relations for oligomers and amorphous polymers," European Polymer Journal, vol. 11, no. 4, pp. 297-300, 1975.

[20] J. M. Widmaier and G. C. Meyer, "Glass transition temperature of anionic polyisoprene," Macromolecules, vol. 14, no. 2, pp. 450-452, 1981.

[21] C. Kow, M. Morton, L. J. Fetters, and N. Hadjichristidis, "Glass transition behavior of polyisoprene: the influence of molecular weight, terminal hydroxy groups, microstructure, and chain branching," Rubber Chemistry and Technology, vol. 55, no. 1, pp. 245-252, 1982.

[22] J. Zhao, M. D. Ediger, Y. Sun, and L. Yu, "Two DSC glass transitions in miscible blends of polyisoprene/poly (4-tertbutylstyrene)," Macromolecules, vol. 42, no. 17, pp. 6777-6783, 2009.

[23] A. Kongkaewa and J. Wootthikanokkhana, "Polymerization of isoprene by using benzyl diethyldithiocarbamate as an iniferter," Science Asia, vol. 25, no. 1, pp. 35-41, 1999.

[24] J. Tsurugi, T. Fukumoto, M. Yamagami, and H. Itatani, "Radiation-induced cis-trans isomerization of polyisoprenes and temperature dependence of the equilibria," Journal of Polymer Science Part A, vol. 4, no. 3, pp. 563-571, 1966.

[25] F. Cataldo, O. Ursini, and E. Lilla, "Radiation induced polymerization of isoprene: a spectroscopic study," Journal of Radioanalytical and Nuclear Chemistry, vol. 275, no. 1, pp. 916, 2008. 

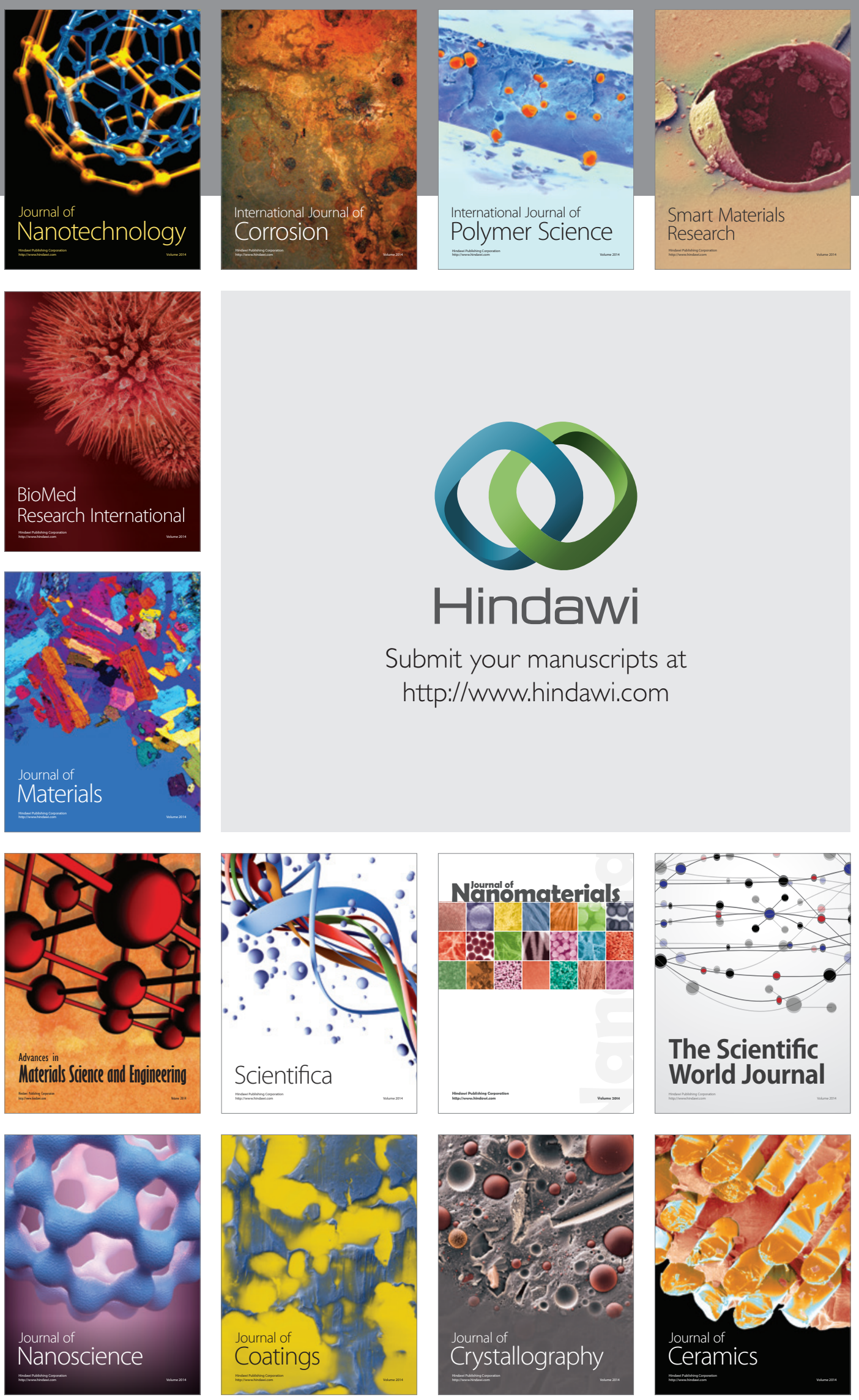

The Scientific World Journal

Submit your manuscripts at

http://www.hindawi.com

\section{World Journal}

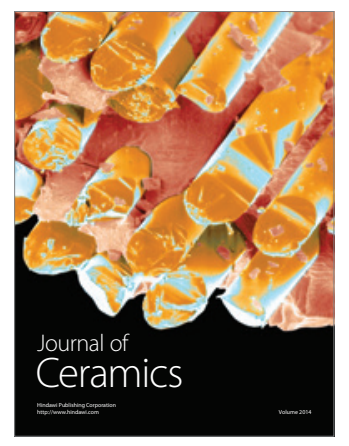

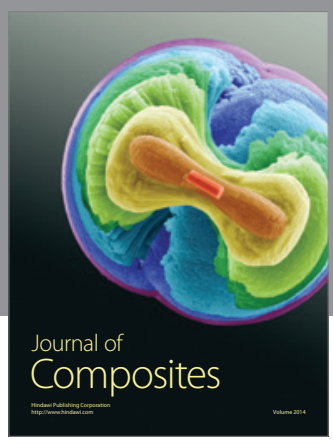
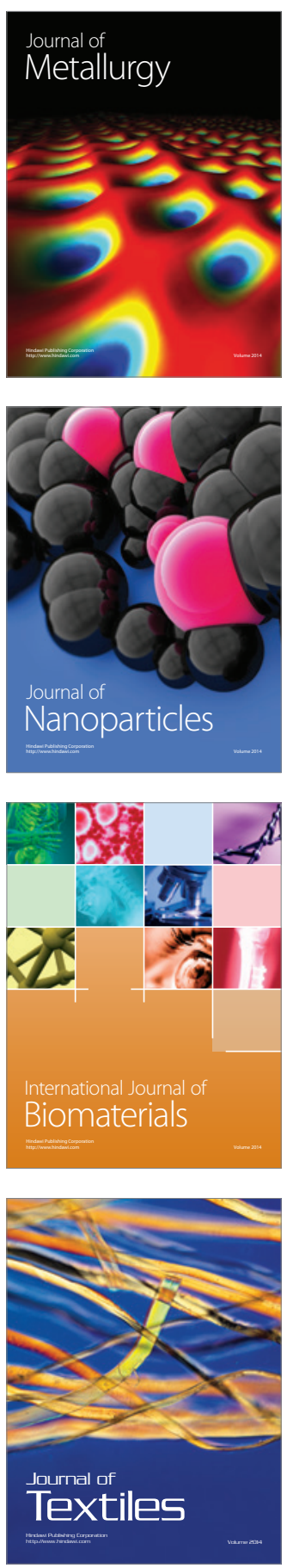